\title{
Psychometric Evaluation of the Role Strain Scale:The Persian Version
}

\author{
Shohreh Kolagari ${ }^{1}$; Mansoureh Zagheri Tafreshi ${ }^{1, *}$; Maryam Rassouli $^{2}$; Amir Kavousi $^{3}$ \\ ${ }_{1}^{1}$ Department of Nursing Management, Faculty of Nursing and Midwifery, Shahid Beheshti University of Medical Sciences, Tehran, IR Iran \\ Department of Nursing Management, Faculty of Nursing and Midwifery, Shahid Beheshti University of Medical Sciences, Tehran, IR
2 Department of Pediatric Nursing, Faculty of Nursing and Midwifery, Shahid Beheshti University of Medical Sciences, Tehran, IR Iran \\ ${ }_{3}$ Department of Pediatric Nursing, Faculty of Nursing and Midwifery, Shahid Beheshti University of Medical Sciences, Tehran, IR Iran
Department of Statistics Sciences, Faculty of Health, Safety and Environment, Shahid Beheshti University of Medical Sciences, Tehran, IR Iran \\ ${ }^{*}$ Corresponding Author: Mansoureh Zagheri Tafreshi, Department of Nursing Management, Faculty of Nursing and Midwifery, Shahid Beheshti University of Medical Sciences, Teh- \\ ran, IR Iran. Tel:+98-2188202519, Fax:+98-2188202519, E-mail: tafreshi45@Hotmail.com \\ Received: October 18, 2013; Revised: January 5, 2014; Accepted: January 28, 2014
}

\begin{abstract}
Background: Nursing teachers have difficulties fulfilling multiple roles expectations and balancing the various dimensions of their roles that may lead to role strain. In order to lack of culturally and academically proper scale in Iran to measure role strain in nursing teachers, localizing a foreign scale in this field is necessary.

Objectives: The objective of this study was psychometric evaluation of the Role Strain Scale (RSS) and confirming its structural model in an Iranian population.

Materials and Methods: The present cross- sectional study was conducted in 2012, comprising 302 nursing teachers from around the country who were selected using stratified-cluster sampling. Psychometric evaluation process of the RSS was carried out by Face, content and constructs validity (confirmatory and exploratory factor analysis). Reliability was examined using test-retest and Cronbach's alpha for internal consistency reliability.

Results: In the primary results, in spite of being approved by face and content validity, in Construct validity, fitness indices of original Role Strain Scale showed no satisfactory findings in Iranian data. Therefore, some items from the structural model of original version were extracted by exploratory factor analysis and a five-factor model with 33 items was obtained. These factors were role conflict, role ambiguity, role overload, role incompetence, and role incongruity. New model as Persian version of RSS was confirmed by calculating fitness indices such as GFI $=0.93, \mathrm{AGFI}=0.94, \mathrm{NFI}=0.91, \mathrm{RMSEA}=0.093$. Internal consistency reliability for the total scale and subscales were respectively 0.92, and 0.71-0.84. Results from Pearson correlation test indicate a high degree of test-retest reliability $(\mathrm{r}=0.89)$. ICC was also 0.91 .

Conclusions: This reliable and valid scale is academically appropriate for nursing teachers to measure role strain and helps detect and predict a multiplicity of role problems and consequently make educational managers aware of nursing teachers' difficulties while facing with multiple roles and possible future challenges.
\end{abstract}

Keywords:Strain; Psychometrics; Evaluation; Nursing

\section{Background}

Due to the changes in work demands of the nursing faculties and clinical setting, nursing teachers are having difficulties fulfilling multiple roles expectations and balancing the various dimensions of their roles (1). Nursing teachers inevitably endure a lot of stress (2), while complex work-related requirements and role necessities are beyond one's performance. If they cannot conduct those role expectations and obligations, it will result in serious problems in role execution which affects both their personal life and teaching outcomes (2, 3). Goode believed "that multiple role obligations and expectations can be a source of role strain" (4). According to Mobily, role strain is characterized as "a subjective status of distress experienced by a role occupant when exposed to role stress" (5) and any person with having multiple roles may be experienced it (6). Many studies reported that role stress and strain may lead to physical and emotional problems such as cardiovascular diseases, tension, anxiety, dissatisfaction and depression which are experienced by nursing teachers while facing different work demands and role expectations in a work setting (1-8). With regard to importance of role strain, Role Strain Scale (RSS) was first developed and its psychometric properties were investigated by Mobily in the U.S. It is a comprehensive instrument used to detect and predict the role problems and work-related stress situations in nursing teacher's. Mobily's scale could appeal to other researchers and has been implemented in other parts of the U.S and adopted cross-culturally in other countries $(3,4,9,10)$. Role strain scale is based on a theoretical framework namely role stress and strain which included three main roots: structure role theory, social exchange theory, and symbolic interaction theory (11). This scale as a self-report questionnaire using the Likert scale includes two sections: demographic variables such as age, gender, marital status, work experience and academic degree, and main part consisting of 44 statements of role strain showing stress-causing situa-

Copyright ( 2014, Iranian Red Crescent Medical Journal; Published by Kowsar. This is an open-access article distributed under the terms of the Creative Commons Attribution-NonCommercial 4.0 International License (http://creativecommons.org/licenses/by-nc/4.0/) which permits copy and redistribute the material just in noncommercial usages, provided the original work is properly cited. 
tions which the respondents usually face. The structural model of the original scale contains seven factors: intersender conflict (four items), intra-sender conflict (nine items), inter-role conflict (four items), role ambiguity (seven items), role overload (eight items), role incongruity (seven items) and role incompetence (five items) (5-11). Surprisingly, no research has been conducted in Iran because no localized comprehensive scale exists for exploring role strain. Since a scale can be a culturebound concept, scales from foreign researches could not be used directly due to the fact that cultural "bias" necessitates assessing psychometric scale (12-14). Therefore, researchers decided to obtain a comprehensive and psychometrical scale for assessing the role strain in academic population in Iran.

\section{Objectives}

The objective of this study was psychometric evaluation of the Role Strain Scale (RSS) and confirms its structural model in an Iranian population.

\section{Materials and Methods}

\subsection{Ethical Views}

The ethical approval was achieved from the Research Ethics Committee of Shahid Beheshti University of Medical Sciences (Code 1391-1-86-10827). Ethical considerations have been taken into account which contains explanations about the research aims to participants and getting consent notes from participants consciously to participate in the research, and the fact that participation is optional and giving assurance to participants about information confidentiality.

Permission for translation, or modification of the RSS was gained from prof. Paula R. Mobily by Email contact (02/10/2012).

\subsection{Study Design}

This study was a cross-sectional research in 2012. The research design included translation procedure and psychometric evaluation consisting of pilot testing of the face and content validity, assessing the construct validity and reliability. Rode believed that "Paying careful attention to the process of psychometric methods and cultural adaptation will ensure the validity and reliability of the Scale" (13).

\subsection{Translation}

Cultural adaptation is aimed at providing compatibility between the original version of the scale and the new one regarding face, content validity (15). A common method to prepare scales for cross-cultural adaptation is translation (16). Severinsson reported that "there are not standard guidelines for the translation of the Scale" (17). We used Wild et al. protocol in the process of translation which included: forward translation, reconciliation, back translation, back translation review, harmonization, cognitive debriefing, results and finalization, and final report (18). Initially, the role strain scale was translated by two professional and experienced Persian translators from English to Persian. The translations were assessed in terms of content and connotation and semantic clarity by the research team and English teachers. Using slight changes, the final translated Persian version of the scale was approved with the most suitable translated phrases. Next, it was once again translated into English by another translator to keep the originality of the main version and its backward translation to English was compared and confirmed by Mobily with the original English version so that it was the same as the original scale, both conceptually and linguistically.

\subsection{Face and Content Validity}

First, to evaluate qualitative face validity, translated Persian version of RSS was piloted with 10 nursing teachers as a target group ( 5 females and 5 males). After the nursing teachers individually completed the questionnaire, they were asked to express their overall perceptions in responding to the statements of questionnaire. Moreover, to assess face validity of the translated Persian version quantitatively, the impact score calculated for each of the 44 items of the scale. A 5-point Likert scale was considered in which the choice of "always" standing for the most important strain was scored as 5 and "never", which means the least important strain, was scored as 1 . Through implementing the formula, items impact scores were calculated $(19,20)$. For qualitative content validity, through interview with 15 experts in the field of nursing and behavioral science, the experts were asked to express their editing ideas (i.e. grammar, wording and scaling of the scale). For quantitative content validity, to assess content validity index (CVI), the experts were also asked to assess relevancy, simplicity and clarity of each item with the content according to Waltz and Bausell index ,Values for CVI are as follows: < 0.70: unacceptable; 0.7-0.78: revision and correction; $\geq$ 0.79: accepted (21).

\subsection{Statistical Analysis}

To establish construct validity, Confirmatory Factor Analysis (CFA) was conducted by LISREL program to ensure that the factor structure of translated Persian version of RSS is similar to the original version. "LISREL and AMOS are programs that can conduct confirmatory factor analysis to release model fit indices (22). As no fitness find, the researchers can modify the model. Severinsson reported "if fit indices could not fit to possible data model, confirmatory factor analysis changes into Exploratory Factor Analysis (EFA)" (17). Fit indices include :The chi-squared goodness-of-fit test $\left(\chi^{2} / \mathrm{df}\right) \leq 3$, the goodness-of-fit index (GFI) $\geq 0.9$, the adjusted good- 
ness-of-fit index (AGFI) $\geq 0.9$, the normed fit index (NFI) $>0.9$ as well as the non-normed fit index $(\mathrm{NNFI})>0.9$, root mean square error of approximation (RMSEA) $<0.1$ and comparative fit index (CFI) $>0.9$ (23). CFA is a pattern of structural equation modeling (SEM)" (17). Prerequisite of CFA is determining sample size, there are differences in recommendations of an acceptable sample size for factor analysis, and some authors recommend five person per item and others ten $(24,25)$. In this study, the recommendent samples for 44 items were among 220 to 440 . To get samples of factor analysis, stratified cluster sampling has been used. To do so, the country has been divided geographically into north, south, west and center as strata and Medical Sciences Universities (Nursing colleges), as cluster, some of the nursing colleges have been selected randomly from among all nursing colleges of the country $(n=23)$. Then all nursing teachers of these colleges who qualified the criteria of this study were given the questionnaire. 375 questionnaires have been distributed out of which 302 questionnaires have been returned. These criteria include having at least one year of work experience as nursing teacher in clinical and theoretical teaching, in the field of research and being official authorities in the college. Hence, the questionnaire was not given to those who did not meet these criteria. Regarding LISREL program is sensitive to normal assumption (23); Kolmogorov-Smirnov test has proved data normality.

\subsection{Reliability}

The internal consistency of the scale was assessed using the Cronbach's alpha coefficient. Values of Cronbach's $\alpha \geq 0.70$ were explained as satisfactory internal consistency $(26,27)$. Furthermore, to assess the stability reliability of test -re-test, and intraclass correlation coefficient (ICC), 30 nursing teachers completed the Persian version of RSS in two-week intervals. ICC values of 0.40 or above were considered satisfactory $(r \geq 0.81-1.0$ as excellent, 0.61- 0.80 very good, 0.41-0.60 good, 0.210.40 fair, and 0.0-0.20 poor) (28). Data were analyzed using Statistical Package (Version 18, SPSS Inc., Chicago, USA) and confirmatory factor analysis was performed with LISREL version 8.8 .

\section{Results}

The results of the quantitative face validity revealed that all of the items had impact scores $\geq 1.5$. Besides, in qualitative part, the nursing teachers' ideas were satisfactory and approved all items of the scale. According to the expert panel opinions, qualitative content validity was approved with some slight changes; and the CVI scores for all items were $\geq 0.80$. The mean content validity index was $92 \%$ for relevancy, $85 \%$ for clarity and $88 \%$ for simplicity. In construct validity, Findings showed that among 375 nursing teachers, 302 nursing teachers completed the anonymous self-report questionnaire and returned it (Response rate $=80.5 \%$ ). Participants who did not return the questionnaire were equally from all geographical areas which did not hurt the balance of sampling the research. The female made up $68.2 \%$ of the samples. The mean age and work experience of nursing teachers was respectively $43.5 \pm 6.5$ and $15.1 \pm 7.4$ years. $85 \%$ of nursing teachers were married, $82.1 \%$ had Master of Science. Table 1 According to the results of construct validity, CFA revealed that translated Persian version of original RSS was not good enough to fit. All indices had poor goodness of fit, they were respectively, $\chi^{2} / \mathrm{df}=4.5$, $\mathrm{CFI}=0.08, \mathrm{GFI}=0.62, \mathrm{AGFI}=0.58, \mathrm{NFI}=0.75, \mathrm{NNFI}=0.79$ and RMSER $=0.12$.

As no fitness was found at confirmatory factor analysis, the only way was exploratory factor analysis to obtain the better model. To do so, initially data was examined by the Bartlett's test of sphericity to reach sample adequacy, [Bartlett's test of sphericity; $\mathrm{P}<0.001 \chi^{2}=6588.192$ and $\mathrm{KMO}=0.818]$. Next, researchers performed several explorative factor analyses among the variables to identify the best model to fit, and finally a five-factor model was selected by item- to factor loading $>0.45$, applying varimax rotation, eigenvalues $>1$. The number of items was deleted (11 items; 2, 5, 6, 18, 21, 22, 36, 8, 20, 43, 44) and the rest of items were forced into a five factor solution. Five-factor model [modify RSS] as the best modified model was extracted, accounting for $64.4 \%$ of the total variance. Fivefactor model comprises 33 items, using the Likert scale (1-5 scores) accepted. Factors are as follows:

Factor 1 (Conflict) including 8 items $[4,16,17,25,26,27$, 28 and 42].

Factor 2 (Incongruity) including 7 items [7, 11, 12, 13, 14, 19 and 24].

Factor 3 (Incompetence) including 6 items [3, 15, 34, 35, 37 and 38].

Factor 4 (Ambiguity) 6 items [31, 32, 33, 39, 40, and 41].

Factor 5 (Overload) 6 items [1, 9, 10, 23, 29 and 30] (Table 2).

\begin{tabular}{lcc}
\hline \multicolumn{3}{l}{ Table 1. Demographic Variables of Nursing Teachers $(\mathrm{n}=302)$} \\
\hline Characteristics & Number & Frequency \\
\hline Gender & & \\
Female & 206 & 68.2 \\
\hline Male & 96 & 31.8 \\
Married status & & \\
\hline Married & 257 & 85 \\
\hline Single & 45 & 15 \\
Academic degree & & \\
\hline PhD & 54 & 17.9 \\
\hline MSc & 248 & 82.1 \\
\hline Age, $y$ & 43.5 & 6.5 \\
\hline Work experience, $\mathbf{y}$ & 15.1 & 7.4 \\
\hline
\end{tabular}




\begin{tabular}{|c|c|c|}
\hline Factors and Items & Factor Loading & Alpha Value \\
\hline Factor 1 Conflict & & 0.78 \\
\hline $\begin{array}{l}\text { Having job demands interfere with other activities of personal importance (family, Leisure and } \\
\text { other interests) (Item 4) }\end{array}$ & 0.722 & \\
\hline $\begin{array}{l}\text { Feeling pressured to maintain clinical competence or a clinical practice without the time to real- } \\
\text { istically do so (Item 16) }\end{array}$ & 0.867 & \\
\hline Feeling pressure for better job performance over and above what I believe is reasonable (Item 17) & 0.746 & \\
\hline $\begin{array}{l}\text { Feeling that I was hired primarily to teach but I am evaluated on the basis of other role expecta- } \\
\text { tions (Item 25) }\end{array}$ & 0.648 & \\
\hline $\begin{array}{l}\text { Feeling that research and publication expectations take time needed for my teaching responsi- } \\
\text { bilities (Item 26) }\end{array}$ & 0.717 & \\
\hline $\begin{array}{l}\text { Feeling that teaching expectations take time needed for my research and publication activities } \\
\text { (Item 27) }\end{array}$ & 0.547 & \\
\hline Feeling that service expectations take time needed for my other role expectations (Item 28) & 0.651 & \\
\hline Dealing with students who are inadequately prepared or poorly motivated (Item 42) & 0.494 & \\
\hline Factor 2 Incongruity & & 0.84 \\
\hline Feeling torn between the demands of the profession and those of the institution (Item 7) & 0.732 & \\
\hline Receiving insufficient recognition for my teaching performance (Item 11) & 0.849 & \\
\hline Receiving insufficient recognition for my clinical expertise (Item 12) & 0.912 & \\
\hline Receiving insufficient recognition for my research and publications (Item 13) & 0.779 & \\
\hline Receiving insufficient recognition for service activities (Item 14) & 0.811 & \\
\hline Feeling that my progress on the job is not what it could or should be (Item 19) & 0.616 & \\
\hline $\begin{array}{l}\text { Feeling that the goals and values of the institution/department are incongruent with personal } \\
\text { goals and values (Item 24) }\end{array}$ & 0.506 & \\
\hline Factor 3 Incompetence & & 0.76 \\
\hline Coping with the complexity of my job expectations (Item 3 ) & 0.677 & \\
\hline $\begin{array}{l}\text { Feeling unable to satisfy the conflicting demands of my various work-related constituencies } \\
\text { (Item 15) }\end{array}$ & 0.781 & \\
\hline Feeling that I do not have sufficient knowledge and skills to do research (Item 34) & 0.570 & \\
\hline Feeling that I have not kept abreast of current developments in my field (Item 35) & 0.764 & \\
\hline Feeling that I do not have sufficient skills to be an effective teacher (Item 37) & 0.605 & \\
\hline Being concerned that I do not have sufficient clinical expertise (Item 38) & 0.492 & \\
\hline Factor 4 Ambiguity & & 0.71 \\
\hline Feeling uncertain as to what administration thinks of me (Item 31) & 0.832 & \\
\hline $\begin{array}{l}\text { Feeling that there is lack of consensus among faculty on the expectations of the faculty role(Item } \\
\text { 32) }\end{array}$ & 0.788 & \\
\hline $\begin{array}{l}\text { Feeling that there is lack of consensus between faculty and administration on the expectations of } \\
\text { the faculty role (Item 33) }\end{array}$ & 0.750 & \\
\hline $\begin{array}{l}\text { Receiving insufficient information on my performance with respect to promotion and/ortenure } \\
\text { (Item 39) }\end{array}$ & 0.689 & \\
\hline $\begin{array}{l}\text { Receiving insufficient information on my performance with respect to salary considerations } \\
\text { (Item 40) }\end{array}$ & 0.668 & \\
\hline Dealing with unsystematic evaluation practices (Item 41) & 0.534 & \\
\hline Factor 5 Overload & & 0.77 \\
\hline Coping with the number of my expectation of my job (Item 1 ) & 0.682 & \\
\hline Feeling pressured to secure outside funding in a time of limited availability (Item 9) & 0.562 & \\
\hline $\begin{array}{l}\text { Feeling like I have too heavy a workload, one that cannot possibly be finished during the normal } \\
\text { work week (Item 10) }\end{array}$ & 0.775 & \\
\hline Feeling pressured to do more than I currently am (Item 23) & 0.753 & \\
\hline Feeling physically drained from my work at the end of the day (Item 29) & 0.682 & \\
\hline Feeling emotionally drained from my work at the end of the day (Item 30) & 0.853 & \\
\hline
\end{tabular}


Kolagari S et al.

\begin{tabular}{|c|c|c|c|c|c|c|c|c|c|}
\hline Fit indices of Persian RSS & $x^{2}$ & df & $\chi 2 / \mathrm{df}$ & CFI & GFI & AGFI & NFI & NNFI & RMSER \\
\hline & 129.6 & 48 & 2.7 & 0.94 & 0.93 & 0.94 & 0.91 & 0.92 & 0.093 \\
\hline
\end{tabular}

a Abbreviations: AGFI, adjusted goodness-of-fit index; CFI, comparative fit index; GFI, goodness-of-fit index; NFI, normed fit index; NNFI, non-normed fit index; RMSER, rocky mountain service, employment, redevelopment.

Table 4. Results of Descriptive Statistics of Persian Version of Role Strain Scale ${ }^{\text {a,b }}$

\begin{tabular}{lc}
\hline Subscales of RSS-P & Score \\
\hline Role Overload & $3.28 \pm 0.72$ \\
\hline Role Incongruity & $3.20 \pm 0.76$ \\
Role Conflict & $3.15 \pm 0.70$ \\
\hline Role Ambiguity & $3.03 \pm 0.66$ \\
\hline Role Incompetence & $2.07 \pm 0.52$ \\
\hline
\end{tabular}

a Abbreviation: RSS, Role Strain Scale.

$\mathrm{b}$ Data are presented as Mean \pm SD.

After doing confirmatory factor analysis, all indices showed strong goodness of fit. Finally, this new structural model [modify RSS] as last Persian version of RSS (RSS-P) was good enough to fit in Iranian data Table 3. The results of reliability showed that the Cronbach's alpha coefficient for the RSS-P was 0.92 VS 0.89 for original RSS and for its subscales ranged from 0.71 to 0.84 against 0.57-0.86. In addition, Pearson correlation test of the scale approved correlation between the responses in the two times $(r=0.89)$, the ICC was obtained 0.91 and for the subscales, it was good to excellent (0.64-0.85). After obtaining Persian version of role strain scale as a valid and reliable scale, the quantitative analysis conducted and the results revealed that none of nursing teachers had ceiling and floors scores, therefore its effect was not present in this research, Moreover, the mean of role strain in nursing teachers has been measured and the role strain scores has been obtained by calculating mean of individual responses to items: very weak (1-2.59), weak (2.60-2.99), Moderate (3-3.49) and severe (3.5-5). The results showed that role strain total score mean is 3.48 (0.23) Table 4.

\section{Discussion}

All in all, the results of study indicated that RSS-P is a valid and reliable scale for measuring role strain. Face validity was approved by target groups' satisfaction with the quality of the scale items and satisfactory results obtained by calculating impact score. Both quantity and quality of content validity were verified by expert panel ideas with slight differences which were in line with Chang and Hanna (2-10). Construct validity was evaluated by confirmatory factor analysis. In this research, response rate was $80.5 \%$. Polit and Beck reported that scale response rate of over $50 \%$ is satisfactory (29). After analysis by LISREL, in the primary results, fitness indices showed that the structure and relations among concepts of the original scale were not appropriate for Iranian data which can be explained by the language and cultural factors as Severinsson reported "while the translation of questionnaires for cross-cultural research is important, methodological pitfalls problematic for validity may arise" (17). In these conditions, the researchers can modify the model (22). In other word, confirmatory factor analysis changes into exploratory factor analysis to find a favorite structural model (17). Initially, the KaiserMayer-Olkin (KMO) measurement showed that the sample size was adequate for exploratory factor analysis, as Andersson maintained the KMO value over 0.6 is satisfactory for factor analysis (30). At last, a new model has been developed by doing several exploratory analyses, having a factor loading $>0.45$ and deleting 11 items, which was a reason for irrelevance of these items with role strain scale in Iranian data (31). Garson suggested that "factor loadings of $<0.4$ are weak and factor loadings $\geq 0.6$ are very strong" (32). This new model (RSS-P) Contains 5 factors which consist of 33 items which were proved by both the statistic evidence (64.4\% of total variance) and theoretical framework. Pett et al. recommended that a newly developed scale should explain $60 \%$ of the total variance (33). Although, the results of the present research was supported by Lin's study, in a sense that it used EFA to evaluate scale items and deleted some of items and came up with a five-factor model appropriate with the data (2), items array in each factor was completely different from our study which refers to academic structure difference and expectations of multiple roles in that society. In this stage, confirmatory factor analysis was conducted to approve new model. "EFA followed by CFA is one of the most common approaches to scale development and validation" (34). The results revealed an accepted good fitness between data and the model. In other words, the CFA supported the EFA results in terms of the dimensions of new scale. This is in line with Xu and Song (35). In their study, the construct validity was also examined through EFA and CFA, EFA was conducted to provide model specification and then CFA was conducted for validation of the model. As expected, RSS-P as a newly developed Scale had higher internal consistency reliability than the original Scale did, which can be related to, on one hand, both cultural similarity of data and model and doing psychometric stages properly (13). On the other hand, modifying model factors which set the ground for increasing internal consistency among the scale items (23). Streiner and Norman reported that internal consistency related to the homogeneity of the Scale" (31). In well-designed Scale, Cronbach's $\alpha \geq 0.7$ is satisfactory level of internal 
consistency (36). In addition, scale stability reliability showed proper correlation among scale items and intraclass coefficient which is supported by other researches $(9,10)$. As results showed that role strain total score mean, was moderate to high and among sub-scales, the highest mean of role strain belongs to role overload, and the lowest mean belongs to role incompetence. The researchers believed that Stress and felt difficulty and tension in fulfilling role obligations and expectations leading to role strain $(4,5)$. Likewise, high work pressure, heaviness of work and a lot of working demands with time shortage led to role overload, and its consequences have influence on personal and organizational life (37, 38). In addition, role incompetence is ranked in the bottom of the table which means nursing teachers benefit from qualification and competence and this sub-scale is no importance in role strain. This finding is in line with other researches $(4,9)$. The researchers encountered no limitations in the current research. As a conclusion, now this reliable and valid scale is academically appropriate to measure role stress and strain. The RSS-P can help detect and predict a multiplicity of role problems and consequently make educational managers aware of nursing teachers' difficulties with facing multiple roles and possible future challenges. Moreover, this scale can benefit from needed potential to be used in comparative studies in different academic societies. As, several measurement of role strain by this scale and comparing the results is more likely to lead to change nursing educational policies and strategic programs of nursing faculties. Thus, the researchers offer more and more studies to be conducted in using this scale to detect role strain and consequently to find ways to decrease and remove role stress and strains, and also they suggest comparative studies in this field. The strength of this study is full accomplishment of psychometric process to provide a valid and reliable scale to determine nursing teachers' role strain for the first time in Iran. While, for weakness of this study, it can be said that using this scale for nursing teachers in clinical teaching who did not deal with multiple roles and expectations and necessities of these roles does not help determine role strain for them, and this problem has been left for future researches. Finally, with regard to the fact that nursing (all fields) is stress-causing in its essence; therefore, developing and/or psychometric evaluation a proper scale for role stress and strain is suggested in other fields of nursing such as clinical nursing, community nursing, maternity nursing, etc.

\section{Acknowledgements}

Our special thanks to the nursing teachers who participated in this study during the process of scale evaluation for helping their knowledge and experiences. We would also like to state our thanks to research deputy of Shahid Beheshti University of Medical Sciences for supporting the study.

\section{Author's Contributions}

Kolagari collected the data, carried out the analysis and wrote the article. Zagheri-Tafreshi supervised the study concept and design and contributed to writing process. Rassouli contributed to the study design and revised the manuscript. Kavousi and Rassouli supervised the statistical analysis and interpretation of data and contributed to the study design. All authors read and approved the manuscript.

\section{Funding/Support}

This study was funded and supported by Shahid Beheshti University of Medical Sciences. Tehran, Iran (Grant No:1391-1-86-10827).

\section{References}

1. Conley S, Woosley SA. Teacher role stress, higher order needs and work outcomes. J Educat Adm. 2000;38(2):179-201.

2. Chang SY.An exploration ofjob impacts and the organizational commitment of clinical nursing instructors at one university in Taiwan. Taiwan: The University of the Incarnate Word; 2006.

3. Hawkins A, Frander E, Lewis S. Cultivating an Environment for Continued Growth in Nurse Educators. J Coll Educ Health Prof. 2012;13(1):39-45.

4. Oermann MH. Work-related stress of clinical nursing faculty. $J$ Nurs Educ. 1998;37(7):302-4

5. Mobily PR. An examination of role strain for university nurse faculty and its relation to socialization experiences and personal characteristics. J Nurs Educ. 1991;30(2):73-80.

6. Barton R, Corban A, Herrli-Warner L, McClain E, Riehle D, Tinner E. Role strain in occupational therapy fieldwork educators. Work 2013;44(3):317-28.

7. Whalen KS. Work-related stressors experienced by part-time clinical affiliate nursing faculty in baccalaureate education. Int J Nurs Educ Scholarsh. 2009;6:Article30.

8. Dua JK. Job stressors and their effects on physical health, emo tional health and job satisfaction in a university. J Educ Adm. 1994;32(1):59-78.

9. Henning JM, Weidner TG. Role strain in collegiate athletic training approved clinical instructors. J Athl Train. 2008;43(3):275-83.

10. Hanna C. The relationship between nursing education reform factors and undergraduate nursing faculty role strain.. USA: Widener University; 2000.

11. Brookes K, Davidson PM, Daly J, Halcomb EJ. Role theory: a framework to investigate the community nurse role in contemporary health care systems. Contemp Nurse. 2007;25(1-2):146-55.

12. Moser AM, Traebert J. [Transcultural adaptation of the HIV/AIDSTarget Quality of Life for HIV/AIDS for the evaluation of patients quality of life]. Cien Saude Colet. 2011;16 Suppl 1:1357-62.

13. Rode N. Translation of measurement instruments and their reliability: An example of job-related affective well-being scale. Metodoloski zvezki.2005;2(1):15-26.

14. Carrico G, Meves R, Avanzi O. Cross-cultural adaptation and validity of an adapted Brazilian Portuguese version of Scoliosis Research Society-30 questionnaire. Spine (Phila Pa 1976). 2012;37(1):E60-3.

15. Beaton DE, Bombardier C, Guillemin F, Ferraz MB. Guidelines for the process of cross-cultural adaptation of self-report measures. Spine (Phila Pa 1976). 2000;25(24):3186-91.

16. Sperber AD. Translation and validation of study instruments for cross-cultural research. Gastroenterology. 2004;126(1 Suppl 1):S124-8.

17. Severinsson E. Evaluation of the Manchester clinical supervision scale: Norwegian and Swedish versions. J Nurs Manag. 2012;20(1):81-9.

18. Wild D, Grove A, Martin M, Eremenco S, McElroy S, Verjee-Lorenz A, et al. Principles of Good Practice for the Translation and Cul- 


\section{Kolagari S et al.}

tural Adaptation Process for Patient-Reported Outcomes (PRO) Measures: report of the ISPOR Task Force for Translation and Cultural Adaptation. Value Health. 2005;8(2):94-104.

19. Juniper EF, Guyatt GH, Streiner DL, King DR. Clinical impact versus factor analysis for quality of life questionnaire construction. JClin Epidemiol. 1997;50(3):233-8.

20. Lacasse Y, Godbout C, Series F. Health-related quality of life in obstructive sleep apnoea. Eur Respir J. 2002;19(3):499-503.

21. Waltz CF, Bausell RB. Nursing Research: Design, Statistics and Computer Analysis.Philadelphia: F. A. Davis Company; 1983.

22. Mueller RO. Basic principles of structural equation modeling: An in troduction to LISREL and EQS.New York: Springer; 1996.

23. Munro BH. Statistical Methods for Health Care Research. Philadelphia: Lippincott Williams and Wilkins; 2005.

24. Worthington RL, Whittaker TA. Scale development research a content analysis and recommendations for best practices. Couns Psychol. 2006;34(6):806-38.

25. Rattray J, Jones MC. Essential elements of questionnaire design and development. J Clin Nurs. 2007;16(2):234-43.

26. Cronbach LJ, Warrington WG. Time-limit tests: estimating their reliability and degree of speeding. Psychometrika.1951;16(2):167-88.

27. DeVon HA, Block ME, Moyle-Wright P, Ernst DM, Hayden SJ, Lazzara DJ, et al. A psychometric toolbox for testing validity and reliability.J Nurs Scholarsh. 2007;39(2):155-64.

28. Maasoumi R, Lamyian M, Montazeri A, Azin SA, Aguilar-Vafaie ME, Hajizadeh E. The sexual quality of life-female (SQOL-F) questionnaire: translation and psychometric properties of the Iranian version. Reprod Health. 2013;10:25.
29. Polit DF, Beck CT. Nursing research Generating and assessing evidence for nursing practice.Philadelphia: Lippincott Williams and Wilkins; 2008.

30. Andersson BT, Christensson L, Fridlund B, Broström A. Development and psychometric evaluation of the radiographers' competence scale. Open J Nurs. 2012;2(2):85.

31. Streiner DL, Norman GR. Health measurement scales: a practical guide to their development and use. 4th ed: Oxford university press; 2008.

32. Garson D. Statnotes:Topics in Multivariate Analysis: Factor Analy sis. 2010. Available from: http://faculty.chass.ncsu.edu/garson/ pa765/statnote.htm.

33. Pett MA, Lackey NR, Sullivan JJ. Making sense of factor analysis: The use of factor analysis for instrument development in health care research.London: SAGE Publications; 2003.

34. Cabrera Nguyen P. Author guidelines for reporting scale development and validation results in the Journal of the Society for Social Work and Research. J Soc Soc Work Res. 2010;1(2):99-103.

35. Xu L, Song R. Development and validation of the work-familyschool role conflicts and role-related social support scales among registered nurses with multiple roles. Int J Nurs Stud. 2013;50(10):1391-8.

36. Nunnally JC, Bernstein IH. Psychometric theory.New York: McGrawHill; 1994.

37. Fong CM. Role overload, social support, and burnout among nursing educators. J Nurs Educ. 1990;29(3):102-8.

38. McVicar A. Workplace stress in nursing: a literature review. J Adv Nurs. 2003;44(6):633-42. 